\title{
Photosymbiosis for Biomedical Applications
}

\author{
Myra N. Chávezit, Nicholas Moellhoff2t, Thilo L. Schenck ${ }^{2}$, José Tomás Egaña ${ }^{3 *}$ and \\ Jörg Nickelsen ${ }^{*}$
}

${ }^{1}$ Molecular Plant Science, Department Biology I, Ludwig-Maximilians-Universität München, Munich, Germany, ${ }^{2}$ Division of Hand, Plastic and Aesthetic Surgery, University Hospital, Ludwig Maximilian Universität München, Munich, Germany, ${ }^{3}$ Institute for Biological and Medical Engineering, Schools of Engineering, Biological Sciences and Medicine, Pontificia Universidad Católica de Chile, Santiago, Chile

Without the sustained provision of adequate levels of oxygen by the cardiovascular system, the tissues of higher animals are incapable of maintaining normal metabolic activity, and hence cannot survive. The consequence of this evolutionarily suboptimal design is that humans are dependent on cardiovascular perfusion, and therefore highly susceptible to alterations in its normal function. However, hope may be at hand. "Photosynthetic strategies," based on the recognition that photosynthesis is the source of all oxygen, offer a revolutionary and promising solution to pathologies related to tissue hypoxia. These approaches, which have been under development over the past 20 years, seek to harness photosynthetic microorganisms as a local and controllable source of oxygen to circumvent the need for blood perfusion to sustain tissue survival. To date, their applications extend from the in vitro creation of artificial human tissues to the photosynthetic maintenance of oxygen-deprived organs both in vivo and ex vivo, while their potential use in other medical approaches has just begun to be explored. This review provides an overview of the state of the art of photosynthetic technologies and its innovative applications, as well as an expert assessment of the major challenges and how they can be addressed.

Keywords: transgenic microalgae and cyanobacteria, photosynthetic oxygen, hypoxia, regenerative medicine, tissue engineering, recombinant proteins and monoclonal antibodies

\section{INTRODUCTION}

Molecular oxygen is essential for cell metabolism and energy production. Consequently, the adaptive response to oxygen fluctuations is one of the most important coupling mechanisms in animal cells and tissues, as revealed by the ground-breaking discoveries recognized by the 2019 Nobel Prize in Physiology and Medicine. In intact tissues, oxygenation is provided by the circulatory system. Loss or absence of blood perfusion eventually leads to severe tissue necrosis-and even localized damage to the microvasculature through surgical interventions, trauma, diabetes, compromised vasculature integrity or peripheral arterial disease-can lead to tissue hypoxia and subsequent functional impairment (Gordillo et al., 2003; Sen, 2009).

Moreover, oxygen is of central importance for tissue regeneration and a crucial mediator of wound healing, since it is involved in every stage of the reparative process, including collagen synthesis, angiogenesis, and epithelialization (Rodriguez et al., 2008; Sen, 2009; Thom, 2011; Eisenbud, 2012). Besides, adequate supplies of oxygen to wound sites are required not only to 
maintain high ATP levels in hypermetabolic proliferating cells, but also for the generation of reactive oxygen species, which act as key signaling molecules in regenerative pathways and play a central role in preventing wound infections. The implications of hypoxia for tissue subsistence and repair have been reviewed extensively, and recent studies have focused on boosting oxygen levels in wounds by providing alternative sources of oxygen, such as topical oxygen therapy, oxygen-releasing wound dressings, supplemental oxygen therapy or hyperbaric oxygen chambers. However, these measures have shown limited success and have not become part of routine clinical practice (Kim et al., 2007; Kimmel et al., 2016; De Smet et al., 2017; Sanford et al., 2018).

On the other hand, certain clades of organisms have acquired oxygen-producing capacities through the incorporation of photosynthetic microalgae or cyanobacteria. Stimulated by these examples of photosymbiotic relationships in nature, the emergence of photosynthetic biotechnology represents a major opportunity to address hypoxia-related issues in regenerative medicine, tissue engineering and even cancer treatment. Furthermore, the combination of biotechnological approaches with photosynthetic organisms opens up the prospect of reversing the life-threatening impact of a hypoxic microenvironment in other medical conditions such as stroke, myocardial infarction and organ transplantation (Table 1). In the following, we describe the principles and assumptions behind the photosynthetic technologies devised so far, summarize the main findings and review their shortcomings, with the aim of promoting their further development and extending the scope of their applications.

\section{PHOTOSYMBIOSIS IN NATURE}

Photosynthesis mediates the conversion of solar energy into biomass, and has had an immense influence on geochemical and biological evolution since its advent ca. 2.4 billion years ago (Hohmann-Marriott and Blankenship, 2011). Photosynthetic light reactions take place within specialized membrane systems named thylakoids in cyanobacteria, algae and plants. These membranes harbor the main constituents of the photosynthetic electron transport (PET) chain, i.e., photosystem II, the cytb $\mathrm{f}_{\mathrm{f}}$ complex and photosystem I, which generate a protonmotive force that is used for the production of ATP. Strikingly, the initial steps of PET in photosystem II produce molecular oxygen as a byproduct, which extracts electrons from water. These electrons are then used to fuel the PET (Nickelsen and Rengstl, 2013). Thus, PSII functions as a light-driven oxidoreductase, which comprises more than 20 subunits and numerous low-molecularweight cofactors, including organic pigments like chlorophylls and carotenoids as well as essential inorganic constituents such as iron and manganese. Indeed, the last-named metal is essential for oxygen production, as it forms part of the $\mathrm{Mn}_{4} \mathrm{O}$ cluster that catalyzes photon-driven water oxidation (Shen, 2015).

Photosynthetic organisms, also known as phototrophs, use the chemical energy generated by the PET for the synthesis of carbohydrates, lipids and proteins, thereby producing the metabolites required to sustain not only their own survival but also that of the heterotrophs that feed on them. Among the most remarkable of ecological relationships is photosymbiosis - the stable mutualistic, extra- or intracellular, symbiotic association between a heterotrophic organism and a photosynthetic protist. Examples of photosymbiosis are found among sponges, cnidarians, flatworms, molluscs, ascidians and even some vertebrates. These organisms have evolved to establish and maintain symbiotic relationships by hosting photosynthetic bacteria, cyanobacteria or unicellular algae under a common principle of exchange, in which the symbiont provides its host with organic carbon metabolites produced through photosynthesis, while the host organism offers protection from predators and environmental hazards, plus a supply of inorganic compounds, such as carbon dioxide, which serve as metabolites for the photosynthetic organisms. Since such interactions result in the host's acquisition of many of the benefits of photosynthesis (Melo Clavijo et al., 2018), these relationships have been described as a "domestication of photosynthesis that can result in atrophic independence (...) under the infinite source of solar energy" (Bailly et al., 2014), and it may cover up to $90 \%$ of the host's energy requirements (Kühlmann, 1993), and an estimate of $50 \%$ of all marine photosynthesis (Bailly et al., 2014). Intriguingly, while the genetic mechanisms that have allowed the establishment of photosymbiosis have been actively studied (Melo Clavijo et al., 2018), the relevance of oxygen production within these relationships has only begun to be understood.

For instance, reef-building corals form an endosymbiotic relationship with dinoflagellate algae belonging to the genus Symbiodinium, which take up residence and remain photosynthetically active within the endodermal tissue of the cnidarian. The impact of this photosymbiotic association between algae and host is so great that it is considered to be the key to understanding the environmental problem of coral bleaching. This phenomenon, in which an initial photosynthetic impairment in the endosymbiotic algae, owing to loss of the photosynthetic pigments, leads to the subsequent expulsion of Symbodinium from the host, has been correlated with a response to thermal stress (Hill et al., 2014). Moreover, the presence and photosynthetic potential of Symbodinium spp. increases the ability of Cassiopea sp. polyps to cope with the effects of ocean acidification, as it may mitigate the combined effects of hypoxia and the drop in the $\mathrm{pH}$ of seawater (Klein et al., 2017). Interestingly, a recent study of the molecular mechanisms involved in adaptation to variations in oxygen concentrations in cnidarians identified conserved oxygen-dependent signal transduction mechanisms, similar to the transcriptional response mediated by hypoxia-inducible factor-1 (HIF-1) in mammals. Since corals are not susceptible to the rapid transition between hyperoxia during the day and intra-tissue hypoxia at night, the authors of this study proposed these invertebrate animals as an insightful model in which to investigate the evolution of regulatory mechanisms of oxygen homeostasis (Zoccola et al., 2017).

Marine metazoans are also well-known to have taken advantage of photosynthesis, and some such symbiotic relationships have become essential for survival. For example, 
TABLE 1 | Organisms employed for photosynthetic oxygenation in medical applications.

\begin{tabular}{|c|c|c|c|c|c|}
\hline Species & Classification & Relevant attributes & Biomedical application & Illumination & References \\
\hline \multirow[t]{2}{*}{ C. reinhardtii } & $\begin{array}{l}\text { Unicellular eukaryotic green } \\
\text { alga of the genus } \\
\text { Chlamydomonas }\end{array}$ & $\begin{array}{l}\text { Model organism in areas such as flagellar } \\
\text { function, photobiology, photosynthesis and } \\
\text { recombinant protein synthesis. Optimal cell } \\
\text { growth between } 20 \text { and } 25^{\circ} \mathrm{C} \text { in defined } \\
\text { salt-based liquid or agar media at neutral pH }\end{array}$ & $\begin{array}{l}\text { - Proof-of-principle of alga-vertebrate } \\
\text { symbiosis Photosynthetic dermal } \\
\text { scaffolds. } \\
\text { - Photosynthetic sutures. } \\
\text { - Photosynthetic gene therapy for } \\
\text { expression and delivery of recombinant } \\
\text { proteins }\end{array}$ & $\begin{array}{l}\text { Constant illumination, white light } \\
\left(1,500-2,500 \text { lux, } 72.5 \mu \mathrm{mol} \mathrm{m}^{-2} \mathrm{~s}^{-1}\right)\end{array}$ & $\begin{array}{l}\text { Hopfner et al., 2014; Alvarez } \\
\text { et al., 2015; Schenck et al., } \\
\text { 2015; Chávez et al., 2016; } \\
\text { Centeno-Cerdas et al., } 2018\end{array}$ \\
\hline & & & $\begin{array}{l}\text { - "Green bioprinting" of 3D alginate } \\
\text { photosynthetic scaffolds }\end{array}$ & $\begin{array}{l}\text { Constant illumination or } 14 / 10 \mathrm{~h} \text { L/D } \\
\text { cycles, warm-white light-emitting diode } \\
\text { panel }\left(20 \mu \mathrm{mol} \mathrm{m} \mathrm{m}^{-2} \mathrm{~s}^{-1}\right)\end{array}$ & $\begin{array}{l}\text { Krujatz et al., 2015; Lode et al., } \\
2015\end{array}$ \\
\hline \multirow[t]{2}{*}{ C. littorale } & $\begin{array}{l}\text { Unicellular eukaryotic green } \\
\text { alga of the genus } \\
\text { Chlorococcum }\end{array}$ & $\begin{array}{l}\text { Highly } \mathrm{CO}_{2} \text {-tolerant green alga with a growth } \\
\text { rate optimum at } 22^{\circ} \mathrm{C} \text { that has been } \\
\text { investigated for photoautotrophic lipid } \\
\text { production }\end{array}$ & $\begin{array}{l}\text { - In vitro oxygenation of multilayered } \\
\text { cell-sheet-based bioartificial cardiac } \\
\text { tissue }\end{array}$ & $\begin{array}{l}\text { Constant illumination (500-700 lux, or } \\
1313 \pm 45 \text { lux) }\end{array}$ & Haraguchi et al., 2017 \\
\hline & & & & $\begin{array}{l}\text { Illumination with an LED light source } \\
\left(30-170 \mu \mathrm{mol} \mathrm{m} \mathrm{m}^{-2} \mathrm{~s}^{-1}\right)\end{array}$ & Ota et al., 2015a,b \\
\hline C. pyrenoidosa & $\begin{array}{l}\text { Unicellular eukaryotic green } \\
\text { algae of the genus Chlorella }\end{array}$ & Grows optimally at $37^{\circ} \mathrm{C}$ and $\mathrm{pH} 7.4$. & $\begin{array}{l}\text { - Implementation in the development of } \\
\text { a photosynthetic artificial lung }\end{array}$ & $\begin{array}{l}\text { Illumination with } 400 \mathrm{~W} \mathrm{Hg} \text {-metal halide } \\
\text { hybrid lamp (luminous flux of } 28,000 \\
\text { lumens, color rendering index of } 91 \text {, and } \\
\text { chromaticity of } 5200 \mathrm{~K} \text { ) and } 300 \mathrm{~W} \text { of } \\
\text { plant grow lights }\end{array}$ & Basu-Dutt et al., 1997 \\
\hline \multirow[t]{2}{*}{ C. vulgaris } & $\begin{array}{l}\text { Unicellular eukaryotic green } \\
\text { algae of the genus Chlorella }\end{array}$ & $\begin{array}{l}\text { Has emerged as a promising alternative } \\
\text { feedstock and nutritional supplement with } \\
\text { anticancer and anti-inflammatory effects. } \\
\text { Optimal growth at } 30^{\circ} \mathrm{C}, \mathrm{pH} \text { 8.2-8.7. Contains } \\
\text { a large concentration of chlorophyll }\end{array}$ & $\begin{array}{l}\text { - Photosynthetic oxygenation of } \\
\text { explanted pancreatic tissue }\end{array}$ & $\begin{array}{l}\text { Illumination for } 30 \text { min., LED lights } \\
(70,000 \text { lux })\end{array}$ & Yamaoka et al., 2012 \\
\hline & & & $\begin{array}{l}\text { - Potential use as an } \\
\text { oxygen-generating system to enhance } \\
\text { radio- and photodynamic cancer } \\
\text { therapy }\end{array}$ & $\begin{array}{l}\text { Constant illumination, cool white } \\
\text { fluorescent light (3,000 lux); Illumination } \\
\text { for } 2 \mathrm{~h} \text {, red light diode ( } 660 \mathrm{~nm}, 6,000 \text { lux) }\end{array}$ & $\begin{array}{l}\text { Morimoto et al., 1995; Qiao } \\
\text { et al., } 2020\end{array}$ \\
\hline \multirow[t]{2}{*}{ C. sorokiniana } & $\begin{array}{l}\text { Unicellular eukaryotic green } \\
\text { algae of the genus Chlorella }\end{array}$ & $\begin{array}{l}\text { Potential for application in wastewater } \\
\text { treatment and biodiesel production. Tolerates } \\
\text { up to } 42^{\circ} \mathrm{C} \text { and shows high growth rate at } 37^{\circ} \mathrm{C}\end{array}$ & $\begin{array}{l}\text { - Photosynthetic oxygen supply to } \\
\text { encapsulated pancreatic islets }\end{array}$ & $\begin{array}{l}\text { Constant illumination, fiber optic light } \\
\text { source }\end{array}$ & $\begin{array}{l}\text { Bloch et al., 2006; Eladel et al., } \\
2019\end{array}$ \\
\hline & & & & $\begin{array}{l}\text { Constant illumination, tubular fluorescent } \\
\text { lamp }\left(100 \mu \mathrm{mol} \text { photons } \mathrm{m}^{-2} \mathrm{~s}^{-1)}\right.\end{array}$ & $\begin{array}{l}\text { Morimoto et al., 1995; Qiao } \\
\text { et al., } 2020\end{array}$ \\
\hline \multirow[t]{4}{*}{ S. elongatus } & $\begin{array}{l}\text { Unicellular cyanobacterium of } \\
\text { the genus Synechococcus }\end{array}$ & $\begin{array}{l}\text { Has been thoroughly investigated as a } \\
\text { candidate for photoautotrophic biosynthesis in } \\
\text { diverse biotechnological applications, } \\
\text { cultivation optimum at }>30^{\circ} \mathrm{C}\end{array}$ & $\begin{array}{l}\text {-Proof-of-principle of } \\
\text { vertebrate-cyanobacterium symbiosis }\end{array}$ & Constant illumination with strong light & Agapakis et al., 2011 \\
\hline & & & $\begin{array}{l}\text { - Intramyocardial photosynthetic } \\
\text { oxygen supply to alleviate ischemia } \\
\text { upon myocardial infarction }\end{array}$ & $\begin{array}{l}\text { Constant illumination, plant fluorescent } \\
\text { light bulbs }\end{array}$ & Cohen et al., 2017 \\
\hline & & & $\begin{array}{l}\text { - Microalgae-gel patch for healing of } \\
\text { chronic diabetes-associated wounds }\end{array}$ & $\begin{array}{l}\text { Illumination in } 6 \text { cycle-period of } 30 \text { min., } \\
\text { near-infrared light-emitting diode } \\
\left(620-660 \mathrm{~nm}, 0.5 \mathrm{~W} / \mathrm{cm}^{2} \text { power density) }\right.\end{array}$ & Chen et al., 2020 \\
\hline & & & - Photoautotrophic biosynthesis & $\begin{array}{l}\text { Constant illumination, white light ( } 500 \\
\left.\mu \mathrm{mol} \text { photons } \cdot \mathrm{m}^{-2} \mathrm{~s}^{-1}\right) \text {; constant } \\
\text { illumination, artificial cool white light } \\
\left(55 \pm 0.5 \mu \mathrm{mol} \text { photons } \cdot \mathrm{m}^{-2} \cdot \mathrm{s}^{-1}\right)\end{array}$ & $\begin{array}{l}\text { Yu et al., 2015; Sarnaik et al., } \\
2017\end{array}$ \\
\hline
\end{tabular}


the green hydra Hydra viridissima evolved into an endosymbiotic organism by incorporating Chlorella algae, which allow it to survive periods of starvation and also supply these animals with an advantageous mode of camouflage in their aquatic environment (Ishikawa et al., 2016). Even though the physiological role of photosynthetic oxygen in this relationship is still unclear, it has been shown that the presence of the algae affects asexual reproduction and plays a major part in the sexual differentiation of the host (Habetha et al., 2003). Another example of a photosymbiotic relationship is the one between the tidal acoel flatworm Symsagittifera roscoffensis and the green alga Tetraselmis convolutae. Here, it has been estimated that the number of algal cells within each adult flatworm may reach 40,000 (Doonan and Gooday, 1982), and together they maintain a tight equilibrium between photosynthesis and respiration, which allows each species to profit from the other's metabolites. In fact, both the animal's survival and its capacity to develop to maturity are directly dependent on the presence of the algae (Bailly et al., 2014).

Photosymbiosis may even provide a more favorable microenvironment or more specialized adaptations for some higher organisms. For instance, the photosynthetic capacity of insect-induced bud galls in acacia plants contributes to their maintenance and growth, partly by providing oxygen to the insect larvae, but also by compensating for the carbon-sink effect induced by the galls on the host plant (Haiden et al., 2012). Even more surprising is the example of the salamander Ambystoma maculatum, which is the first vertebrate found to harbor intracellular photosynthetic endosymbionts in its tissues throughout its entire lifespan, and provides an especially informative example of the benefits of co-existence with a photosynthetic organism. In the late nineteenth century, Henry Orr first described the presence of single-celled Oophila amblystomatis algae in the immediate vicinity of embryos of the salamander. But it was only a few years ago that Ryan Kerney discovered that the algae were in fact inside the embryos, and not just within the jelly sacs surrounding them (Kerney et al., 2011). Moreover, Kerney's electron microscopic analysis showed that, at points of contact, mitochondria in the salamander cells form clusters adjacent to the algal symbiont, further supporting the hypothesis that photosynthetic oxygen could be directly coupled to mitochondria energy production, which was later proven experimentally (Graham et al., 2013). Studies of the importance of the photosymbiotic relationship between these organisms have further shown that the incorporation of the algae into the salamander embryos elevates the oxygen content of the water in their immediate vicinity (Graham et al., 2013; Small et al., 2014), which in turn promotes the hatching of the embryos and protects them against infections (Tattersall and Spiegelaar, 2008; Kerney, 2011). Besides, it appears that the algae help to clear the nitrogen-rich waste released by the embryo and, even more fascinatingly, they become dormant when removed from their host (Gilbert, 1942, 1944). While the precise mechanism and time point of incorporation of the algae remain to be elucidated, it has been suggested that the symbiotic algae could also be passed directly to the offspring's jelly sacs, since algae have been found in the oviducts of adult female salamanders, which is where the embryo-encompassing jelly sacs form (Kerney et al., 2011; Burns et al., 2017).

The fact that $O$. amblystomatis can stably survive inside the salamander suggests that these unicellular microalgae manage to evade destruction by the vertebrate host's immune system. Attempts to reproduce this photosymbiont-vertebrate interaction under controlled experimental conditions have been undertaken by two independent research groups, who injected photosynthetic Synechococcus elongatus PCC 7942 cyanobacteria (Agapakis et al., 2011) and Chlamydomonas reinhardtii (C. reinhardtii) microalgae (Alvarez et al., 2015), respectively, into zebrafish embryos. In the first study, the authors showed higher biocompatibility of the cyanobacteria (relative to E. coli cells) with the zebrafish embryo. They also showed that the photosynthetic organisms were capable of surviving and proliferating inside mammalian cells when cultured under illumination. In the second study, Alvarez et al. (2015) established viable plant-vertebrate chimeras, and demonstrated that both the injected algae and the zebrafish embryo/larvae could survive for several days after injection, during which time no significant innate immune response against the "photosymbiont" nor any developmental impairment of the host was observed. The results presented in both studies suggest that, up to a certain level, photosynthetic organisms are well tolerated as foreign bodies by the developing zebrafish. Lastly, two studies have attempted to generate plant-animal hybrid cells following strategies based on induced phagocytosis (Jones et al., 1976) and cell fusion (Wada et al., 2016), respectively. However, no stable photosynthetic animal cell line has been created so far.

\section{PHOTOSYNTHETIC APPROACHES FOR TISSUE OXYGENATION}

The direct dependence of animal life on photosynthesis was irrefutably demonstrated in 1772 when Joseph Priestley showed that a mouse would die when it was placed in a sealed compartment but survived if a plant was introduced as well (Priestley, 1772). Almost 200 years later, in a pioneering study, Boerema et al. (1960) demonstrated the feasibility of effective oxygen delivery to tissues in the absence of blood cells, thereby showing that the cardiovascular system could be replaced by an alternative oxygen delivery system. Taking this into account, together with the examples of photosymbiosis in nature, it is intriguing (to say the least!) to investigate whether the phenomenon can be employed to confront the clinical challenges associated with tissue hypoxia (Figure 1).

The first experiments that explored the idea of using microalgae for this purpose go back to 1994, when preliminary studies were conducted toward the development of a photosynthesis-based life-support system for individuals at risk of acute respiratory failure (Basu et al., 1994). Respiratory failure is a condition in which the respiratory system cannot provide for adequate gas exchange, and consequently results in hypoxemia and/or build-up of carbon dioxide. In patients with severe pulmonary dysfunction and end-stage lung diseases, extracorporeal membrane oxygenation (ECMO) has since 


\section{A}

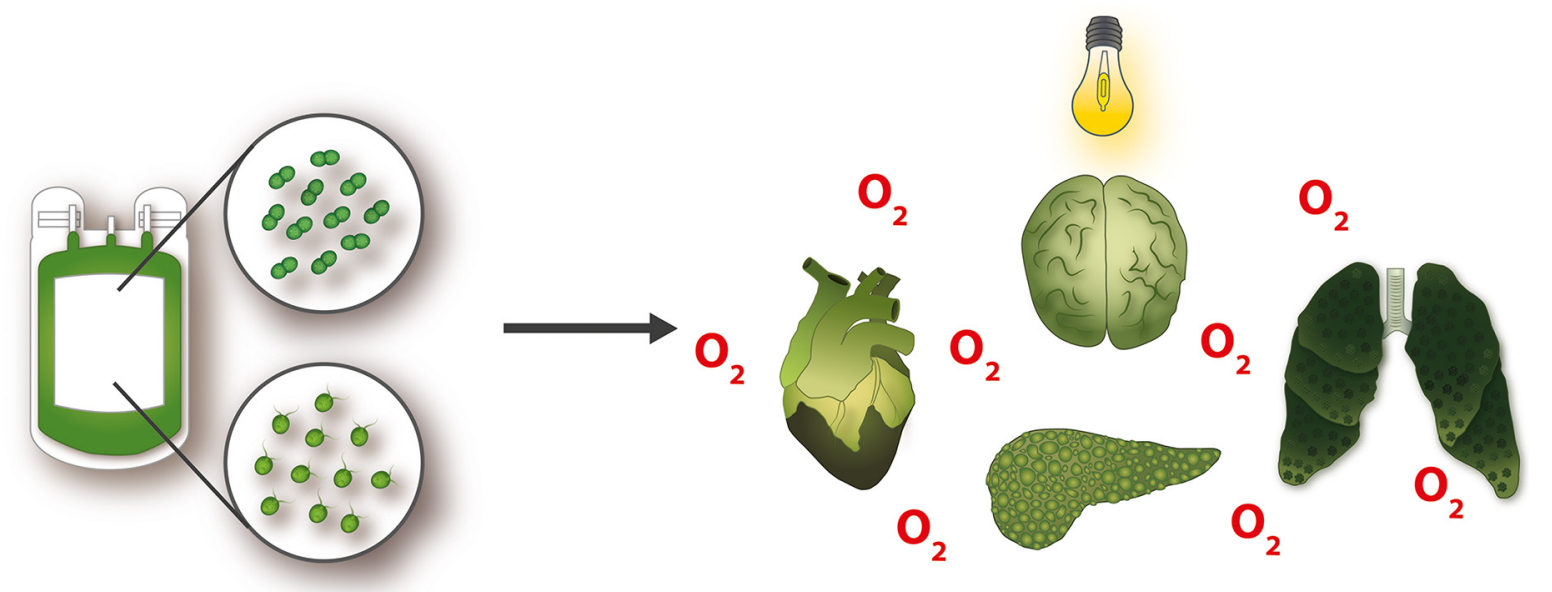

B

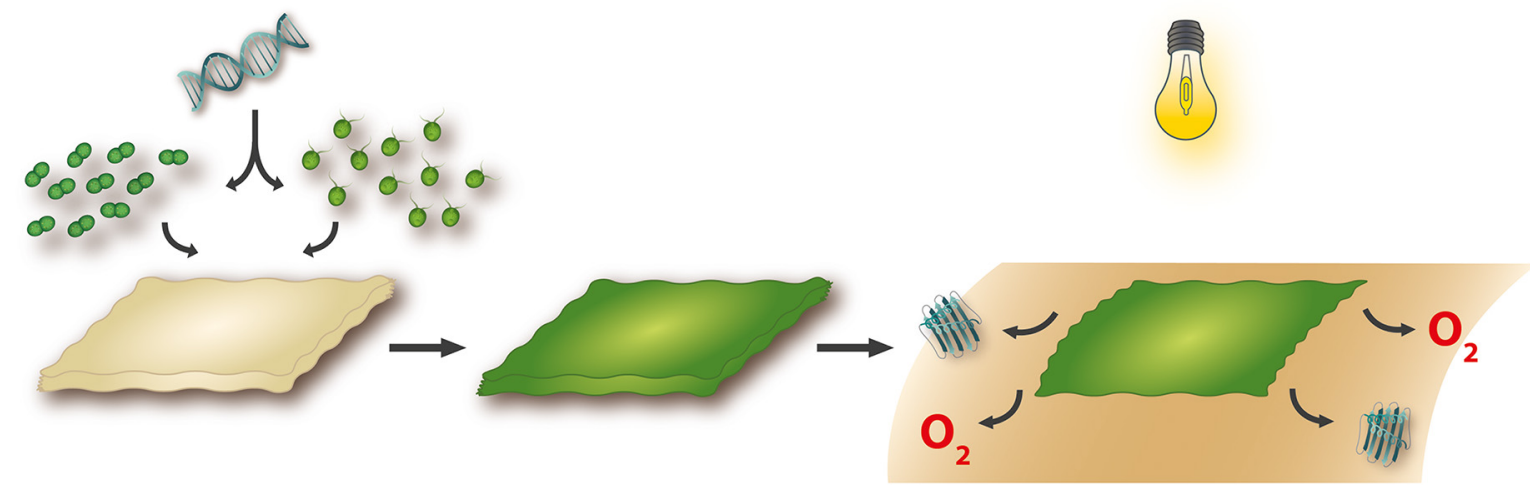

FIGURE 1 | Potential applications for photosynthetic technologies. Novel approaches to organ oxygenation have shown that microorganisms with the capacity to produce oxygen when stimulated with light can improve organ functionality and survival in the absence of blood perfusion (A). Furthermore, the availability of genetic tools makes it possible to construct transgenic photosynthetic organisms that bioactivate tissue-engineered materials and confer upon them the potential to simultaneously and steadily release oxygen and functional recombinant molecules, such as growth factors (B).

evolved as a rescue therapy to maintain oxygenation and $\mathrm{CO}_{2}$ removal. While most patients requiring ECMO are criticalcare patients in intensive care units, some patients requiring long-term ECMO therapy are effectively immobilized owing to the bulkiness of the device, which impairs their quality of life (Makdisi and Wang, 2015). In two subsequent studies (Basu et al., 1994; Basu-Dutt et al., 1997), Basu and collaborators set out to develop a light, portable and energetically efficient "photosynthetic artificial lung" by combining an ECMO unit equipped with an external collector of light energy with a photobioreactor for the cultivation of the green alga Chlorella pyrenoidosa (C. pyrenoidosa). They showed that the algae were capable of photochemically producing $\mathrm{O}_{2}$ and removing $\mathrm{CO}_{2}$ and went on to optimize parameters affecting their photosynthetic efficiency, such as culture medium, cell density, substrate availability and illumination. Then they developed a prototype with which to test the life-support system in vitro by interfacing it with blood via a gas-transfer membrane. While the results obtained were regarded as promising, since the algae were able to supply $\mathrm{O}_{2}$ and remove $\mathrm{CO}_{2}$ at more than half the rate required for physiological applications, the authors concluded that major advances in the design and customization of the photobioreactor would be required before the technology was mature enough for clinical use.

Oxygen deprivation is also a major concern in the field of organ transplantation, in particular for pancreatic tissue. Type 1 diabetes is an autoimmune disorder in which specific loss of pancreatic $\beta$-cells and consequent insulin deficiency result in hyperglycemia (Atkinson et al., 2014). In this context, pancreas transplantation is currently the treatment option of last resort for the restoration of glucose homeostasis and avoidance of lifethreatening diabetic hypoglycemia or ketoacidosis. However, its success depends crucially on the maintenance of organ viability during the interval between donation and transplantation (Giorgakis et al., 2018). To sustain oxygen saturation in the absence of blood perfusion, and maintain functionality over this period, Yamaoka et al. adopted an experimental approach using the photosynthetic microalga Chlorella vulgaris (C. vulgaris) (Yamaoka et al., 2012). In their study, pancreases removed from donor male LEW rats by laparotomy were stored in a gas-permeable, porous pouch containing live algae until implantation. According to the results reported, tissue viability in heterotopically transplanted rat pancreases could be maintained for $3 \mathrm{~h}$ after loss of blood perfusion. Moreover, 
the group of diabetic rats that received organs that had been preserved in this way showed normal glucose regulation and extended survival after surgery, relative to animals treated with pancreatic transplants that had been maintained statically in cold storage, which is currently the standard form of preservation in clinical practice. Most remarkably, in the same study, the authors demonstrated the ability of microalgae to improve the oxygenation of the internal organs of adult male Sprague-Dawley rats with induced respiratory insufficiency.

Thereafter, the idea of oxygen generation using the photosynthetic capacity of microalgae was taken up by Bloch et al. (2006) as a way to overcome severe hypoxia and cell dysfunction caused by the immunoisolation of pancreatic islets and the interruption of vascular connections upon implantation. Pancreatic islet transplantation is an experimental treatment that has been shown to restore $\beta$-cell function, provide glycemic control and achieve sustained insulin independence in diabetics. As yet, its success is directly dependent on the survival of significant numbers of the engrafted pancreatic islets (Gibly et al., 2011). Bloch et al. (2006) sought an experimental means of avoiding this problem by co-encapsulating pancreatic islets isolated from a murine pancreas with Chlorella sorokiniana (C. sorokiniana) in alginate. C. sorokiniana was first shown to produce a significant amount of oxygen in the light, and to survive in the vicinity of mammalian cells. Subsequently, under oxygen-free conditions, co-encapsulated islets were shown to respond to glucose stimulation upon illumination, unlike encapsulated islets alone or co-encapsulates kept in the dark. Furthermore, photosynthetic oxygen supply evoked a higher level of insulin expression than normoxic perfusion, which strongly suggests that photosynthetic oxygen generation by microalgae could potentially bypass hypoxia in bioartificial pancreatic tissues.

Photosynthesis has also been explored as an alternative source of oxygen for the restoration of cardiac tissue subjected to acute ischemia caused by coronary artery disease and myocardial infarct. Cohen et al. reported an unprecedented method for correcting myocardial ischemia, which involves intramyocardial oxygen delivery by Synechococcus elongatus (S. elongatus), a unicellular cyanobacterium with a very high photosynthetic capacity (Cohen et al., 2017). After demonstrating the feasibility of cardiomyocyte-S. elongatus co-culture under (mammalian) physiological conditions, they tested the approach under hypoxic conditions and found that cellular metabolism was indeed enhanced when oxygen production was stimulated by light. Then, the group measured the effect of $S$. elongatus on tissue oxygenation in an acute myocardial infarction model using male immunocompetent Wistar rats. The cyanobacteria were delivered by intramyocardial injection, and ischemia was induced through occlusion of the left anterior descending (LAD) coronary artery. By inducing photosynthetic activity through the exposure of S. elongatus to light, they were able to rescue the myocardium from acute ischemia, and showed that this effect was associated with an increase in tissue oxygenation, and improved cellular metabolism, ventricular function and performance, relative to rats treated by injection of non-illuminated $S$. elongatus and saline controls (Cohen et al., 2017). Importantly, S. elongatus was found to be non-toxic and non-pathogenic in recipient rats, while in a follow-up study, S. elongatus failed to evoke an immune response when injected intravenously into Wistar rats, making this an intriguing and potentially feasible approach for the treatment of myocardial ischemia (Williams et al., 2020).

Finally, a very recent study demonstrated the use of photosynthetic microalgae to potentiate radiotherapy in tumor treatment (Qiao et al., 2020). In this case, C. vulgaris microalgae were coated with membrane components purified from erythrocytes to prevent clearance by macrophages, and then delivered into orthotopic breast cancer tumors in female $\mathrm{Balb} / \mathrm{c}$ mice either directly or via intravenous injection. Increased levels of blood oxygen were observed in the tumor region when photosynthesis was induced by illumination with red light, and in association with X-ray irradiation this measure effectively prevented tumor growth. Moreover, the algae enhanced the therapeutic effect of combined radiation and photodynamic therapy by releasing chlorophyll-derived ROS and reducing the levels of the angiogenic factors HIF1 $\alpha$ and VEGF, thereby promoting cancer-cell apoptosis and inhibiting tumor angiogenesis and proliferation.

\section{PHOTOSYNTHETIC BIOMATERIALS FOR TISSUE ENGINEERING AND REGENERATION}

Photosynthetic microorganisms have found a particular niche within the field of tissue engineering and regeneration (Figure 2), where the regenerative potential of biomaterials is primarily limited by hypoxia (Iyer et al., 2007; Malda et al., 2007; Colom et al., 2014). In this context, Hopfner et al. (2014) first described the development of photosynthetic biomaterials for in-vitro tissue engineering in 2014, using C. reinhardtii as a platform for photosynthesis, together with collagenbased dermal scaffolds. In their study, two- and threedimensional cell co-cultures consisting of $C$. reinhardtii and murine fibroblasts were established to verify the biocompatibility of the heterologous cells. They went on to demonstrate that illumination resulted in a decreased hypoxic response in fibroblasts, owing to the presence of photosynthetic oxygen. This first generation of photosynthetic biomaterials caused a paradigm shift in tissue engineering, by decreasing tissue hypoxia independently of vascularization, perfusion or external oxygen supply. In the following year, Schenck et al. (2015) verified the feasibility of transferring this in vitro concept into living organisms by implanting the photosynthetic biomaterials in murine full-skin defects. For this, they developed an encapsulation technique that enabled them to seed and maintain the algae inside the dermal scaffolds, which promoted both proliferation of the algae and the release of photosynthetic oxygen, as confirmed in vitro. In vivo, they reported high levels of vascularization when these alga-containing implants were exposed to light, and implantation of the photosynthetic scaffolds into female $n u / n u$ athymic mice failed to trigger an immune response. Taking the approach one step further, and motivated by the idea that genetic modification might 

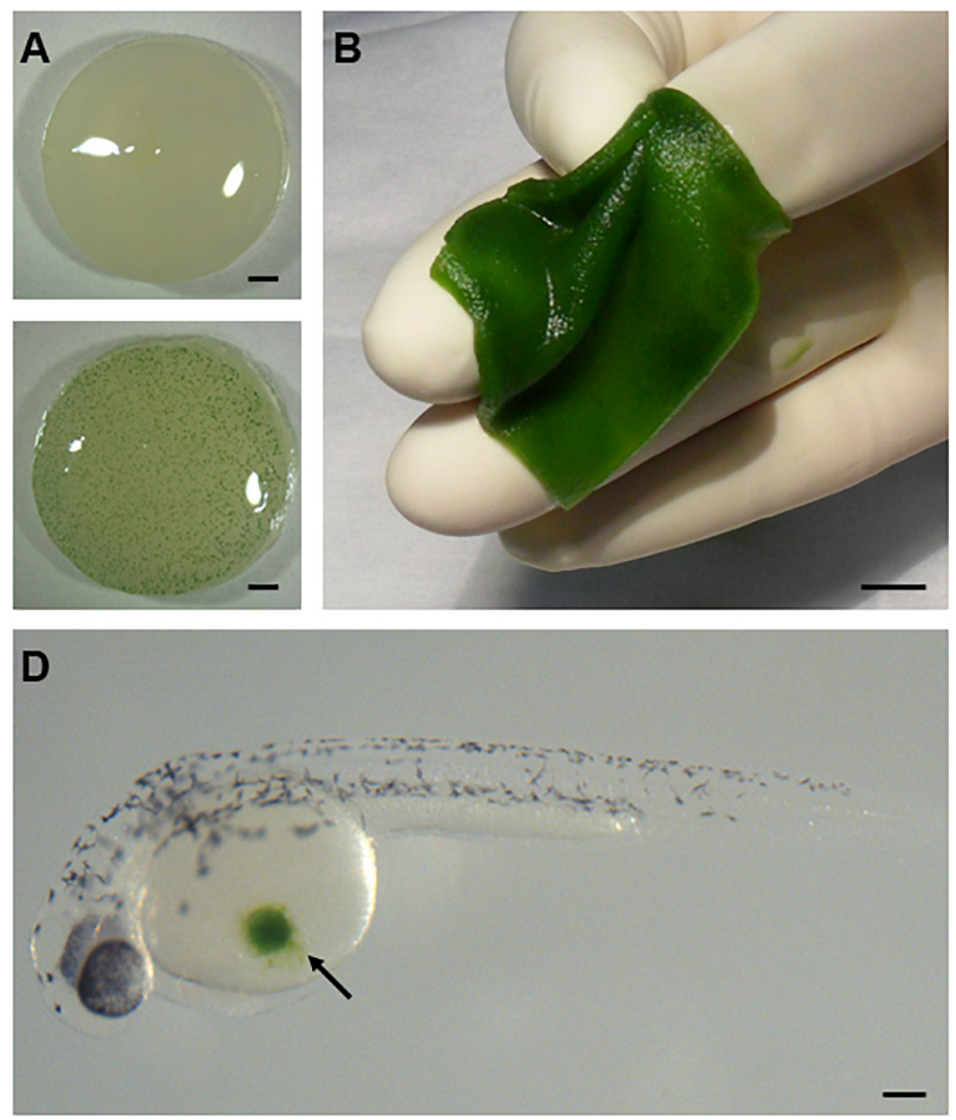
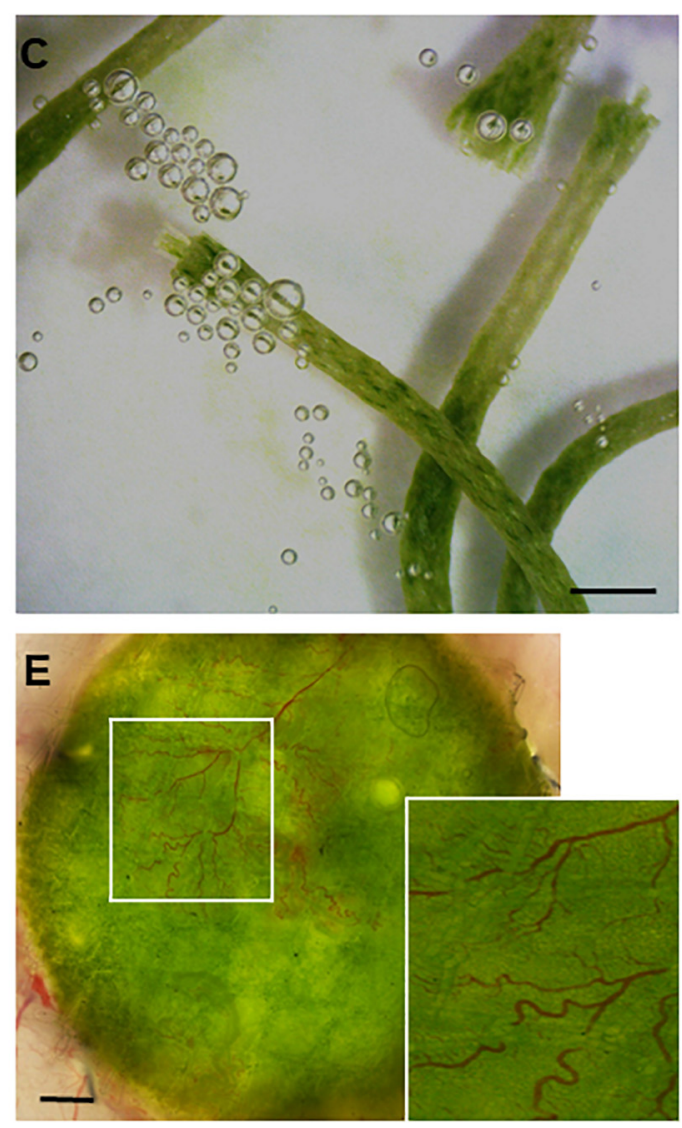

FIGURE 2 | Development of photosynthetic biomaterials. The combination of photosynthetic microorganisms such as cyanobacteria (A) and green algae (B-E) with biomedical devices routinely used in clinical practice, such as dermal scaffolds (B) or suture threads (C), has enabled the development of biomaterials that are capable of producing oxygen in situ. Moreover, the biocompatibility of these organisms with animal life has been demonstrated both in vitro under co-cultivation conditions with mammalian cells and in vivo in several vertebrate models like zebrafish (D) and mice (E). Scale bars represent $1 \mathrm{~mm}$ in (A,C,E), $1 \mathrm{~cm}$ in (B), and $0.2 \mathrm{~mm}$ in (D).

enhance the regenerative potential of C. reinhardtii, Chávez et al. introduced the concept of photosynthetic gene therapy by incorporating transgenic microalgae that secrete recombinant human growth factors, in addition to oxygen, into the scaffolds (Chávez et al., 2016). In this study, they also used immunocompetent hairless female Skh1 mice to prove the safety and biocompatibility of the algal cells over an extended length of time. Finally, the concepts of photosynthetic biomaterials and photosynthetic gene therapy were implemented by the same group to create photosynthetic sutures for the local delivery of oxygen and recombinant growth factors to incisional wounds (Centeno-Cerdas et al., 2018).

Algae other than C. reinhardtii have also been investigated for photosynthetic oxygen release in tissue engineering applications. Chlorococcum littorale (C. littorale) has been used in the generation of three-dimensional (3D) bioartificial cardiac tissues. $3 \mathrm{D}$ cell culture systems, such as cell-sheet-based approaches, have become a major focus in the field of cardiac tissue engineering and regeneration, which aims to grow functionally organized tissue replacements by providing a microenvironment which replicates that of native cardiovascular structures (Cohen et al., 2017). However, the hypoxic microenvironment created when multiple cell sheets are stacked-in the absence of a vascular network-limits the thickness of viable layered 3D tissue to 40-80 $\mu \mathrm{m}$ (Shimizu et al., 2006), which presents a major obstacle to their development and deployment. To overcome this drawback, in 2017 Haraguchi et al. (2017) explored the idea of using C. littorale, a unicellular green spheroidal alga with a high capacity for $\mathrm{CO}_{2}$ fixation and a significant photosynthetic potential (Satoh et al., 2002). By co-culturing multilayer cell sheets composed of rat cardiomyocytes together with $C$. littorale, they were able to bioengineer significantly thicker $(160 \mu \mathrm{m})$ viable tissue consisting of up five cell sheets. Even more remarkably, the authors found significantly lower glucose consumption and lactate production in multilayered sheets co-cultivated with the algae. They attributed this to more effective ATP production, in association with aerobic respiration driven by the increased oxygen supply provided by the algae. Furthermore, significant decreases in both cellsheet delamination and the release of creatine kinase-both common indicators of muscle cell damage-were detected upon histological analysis of the co-cultured cell sheets. Taken together, 
these findings indicate the potential of photosynthetic oxygen supply in the context of the assembly of bioartificial cardiac sheets that could reverse cardiac damage.

Remarkable advances have also been made in the encapsulation of microalgae for bioactivation of tissue engineering constructs. For instance, Lode et al. (2015) demonstrated the feasibility of encapsulating microalgae in three-dimensional alginate scaffolds with a geometry fabricated by computer-based plotting of the optimal fiber network through a rapid prototype method. They used C. reinhardtii as a model organism to show that, upon immobilization in the alginate-based matrix, the algal cells survived the plotting process and could be cultivated within the hydrogel matrix. Moreover, they could be co-incorporated into the network together with human osteosarcoma cells during the fabrication procedure. Later, Krujatz et al. (2015) extended this strategy by investigating the growth and viability of microalgae within 3Dplotted alginate hydrogels and suspension cultures at different temperatures and under various illumination conditions. Interestingly, these authors demonstrated that cell viability was significantly higher when the algae were exposed to a $14 / 10 \mathrm{~h}$ light/dark cycle rather than continuous illumination. Moreover, microalgae embedded within the hydrogel in a highly structured pattern grew at more stable rates than in suspension cultures-irrespective of the illumination conditions, and even at non-ideal temperatures for the algae $\left(26-37^{\circ} \mathrm{C}\right)$. Lastly, in an attempt to enhance the biotechnological production of secondary metabolite production, the same research group went one step further and developed a way to integrate cell cultures of a higher plant (basil) into 3D hydrogel scaffolds (Seidel et al., 2017), thereby achieving a new milestone in what they named "green bioprinting."

During the preparation of this manuscript, a new study appeared which introduced a novel biomedical application of photosynthetic microorganisms as an oxygen source to promote the healing of skin grafts, and chronic diabetes-associated wounds (Chen et al., 2020). The authors developed a patch dressing containing living S. elongatus PCC7942 inside hydrogel beads, with which the wound could be covered, thus allowing gas exchange without eliciting a proinflammatory macrophage response. Under red light irradiation, this "alga-gel patch" produced oxygen, which rapidly and deeply penetrated the skin of immunodeficient Balb/C mice, thereby promoting wound healing and angiogenesis in full-thickness and skin-flap injuries.

\section{TRANSGENIC PHOTOSYNTHETIC ORGANISMS}

Microalgae and cyanobacteria have significant biotechnological potential, owing to their ease of cultivation, fast growth rates, amenability to genetic manipulation, and the availability of complete genome sequences for many species (Rasala and Mayfield, 2015; Kumar et al., 2019). Furthermore, most of these photosynthetic microorganisms have been accorded "GRAS" (generally regarded as safe) status, since they do not carry human pathogens such as viruses, or prions or bacterial endotoxins
(Fields et al., 2020). Thus, their potential can be exploited without the risk of pathogen transmission, and they can even be used for direct applications, such as dermal dressings (Schenck et al., 2015; Chávez et al., 2016), oral vaccines, food additives or nutritional supplements (Gregory and Mayfield, 2014; Gateau et al., 2017; Mysliwa-Kurdziel and Solymosi, 2017). Photosynthetic platforms offer versatility of product targeting, since they merely require the engineering of a transgenic strain to enable the production of a specific product (Mayfield and Golden, 2015). Due to their autotrophic nature, they are viewed as a cost-effective and environmentally friendly platform that offers a number of advantages over alternative approaches to the production of recombinant proteins such as cytokines (RosalesMendoza, 2016), growth factors (Wijffels et al., 2013; Rasala and Mayfield, 2015) and other promising bioactive molecules such as biomaterials (Molino et al., 2016) and enzybiotic proteins, i.e., enzymes designed to have an antibiotic function (Stoffels et al., 2017). The methodology and molecular tools required to generate transgenic photosynthetic organisms capable of producing recombinant biomolecules are now so well established that, to date, more than 45 recombinant proteins have been produced in green algae such as C. reinhardtii, and many more in cyanobacteria (Vijayakumar and Menakha, 2015; Singh et al., 2017). In particular, production of biomolecules in microalgae ensures appropriate translational processing, thereby retaining protein functionality (Scaife et al., 2015), while the option of extracellular secretion targeting makes the purification process less expensive and more straightforward (Ramos-Martinez et al., 2017; Baier et al., 2018). Above all, strategies that allow for the induction of transgene expression in response to heat (Schroda et al., 2002), light (Baek et al., 2016), ethanol (Lee et al., 2018), or hypoxic conditions (Iacopino et al., 2019), which are a current focus of research, could be of great benefit for biomedical applications.

While research on green molecular farming has mainly focused on Chlamydomonas, other microalgae, such as the diatom Phaeodactylum tricornutum, have shown greater potential with respect to post-translational modifications and the assembly of multiple recombinant protein subunits. Examples such as the synthesis of functional human IgG antibodies against hepatitis B virus (HBV) surface proteins (Hempel et al., 2011; Hempel and Maier, 2012) and Marburg virus nucleoprotein (Hempel et al., 2017) have shown that this inducible expression system can efficiently produce and secrete functional monoclonal antibodies at levels of up to $9 \%$ of total soluble protein, with the further advantage of safer and easier downstream processing compared to mammalian cell lines. On the other hand, the advantages of cyanobacteria systems as biotechnological platforms for recombinant protein production are beginning to attract researchers to the field. In particular, the euryhaline unicellular cyanobacterium Synechococcus sp. PCC 7002 (Syn 7002) has recently garnered attention as an industrial host and a novel biomedical tool owing to its fast growth rate, and its tolerance to high light levels, high salt and a wide range of temperatures make it an excellent platform for biotechnological applications. Moreover, its genome has been completely sequenced, while ongoing research on this 
organism is rapidly expanding the molecular toolkit available for genetic manipulation. This now includes promoter design, reporter proteins, selection strategies and overproduction protocols for recombinant protein expression (Ludwig and Bryant, 2012; Ruffing et al., 2016). Promising applications for this cyanobacterial strain include its use to produce biogenic polyphosphate nanoparticles to treat and prevent inflammatory gastrointestinal diseases (Feng et al., 2018a,b, 2019), and hyaluronic acid, a natural polymer with a broad range of cosmetic and biomedical applications (Zhang et al., 2019). Other attractive Synechococcus strains, such as Synechococcus elongatus PCC 7942 and the more recently characterized Synechococcus elongatus UTEX 2973 (Yu et al., 2015), are already being used for the synthesis of bioactive molecules such as heparosan, a pharmaceutical precursor of heparin, and glycosaminoglycans (Sarnaik et al., 2019), including heparan sulfate, chondroitin sulfate and hyaluronic acid, which play key roles in tissue maintenance, repair and regeneration (Melrose, 2016).

Still more impressive is the number and variety of applications that have been found for alga- and cyanobacteria-derived secondary metabolites. The list now includes more than 140 different molecules including polysaccharides, amino acids, carotenoids, isoprenoids, sterols, polyphenolic compounds, fatty acids and halogenated compounds, which are pharmaceutically active when employed as antiviral, antimicrobial and antiinflammatory agents (Riccio and Lauritano, 2020). Besides their value as nutraceuticals, some have shown promising results as anticarcinogenic and antitumor compounds for several multidrug-resistant and advanced cancer types. A recent review has also pointed out the potential of microalgae and cyanobacteria in thalassotherapy (Mourelle et al., 2017), in particular because of the enriched spectrum of biologically active substances they can generate, which are relevant in the context of skincare, rejuvenation and regeneration. However, despite their recognized innate advantage as autotrophic organisms, the full extent of their potential for photosynthetic oxygen production in biomedical settings, and the valuable properties of the compounds they have been shown to synthesize, remains to be explored. For a more detailed consideration of the potential biomedical and pharmaceutical applications of bioengineered cyanobacteria and algae, the authors recommend the following review articles (Mayfield and Golden, 2015; Singh et al., 2017; Dehghani et al., 2019).

As mentioned above, genetically modified photosynthetic microorganisms could boost the regenerative potential of photosymbiotic approaches by combining photosynthetic oxygen supply with the local release of molecules that promote tissue regeneration. Three studies, in particular, have shown how photosynthetic microorganisms could be used to stimulate wound healing by creating an actively supportive microenvironment at the wound site itself. In the first, Chávez et al. (2016) engineered a genetically modified C. reinhardtii strain to constitutively express the human vascular endothelial growth factor VEGF-165 (hVEGF) with the aim of boosting the pro-angiogenic effect of photosynthetic dermal scaffolds. The authors showed that overexpression of recombinant hVEGF by these algal cells following their implantation in immunocompetent mice promoted endothelial cell migration and blood vessel formation, whereas blood vessel ingrowth was observed after injection of the transgenic microalgae into the yolk sac of zebrafish embryos. In the second study, Centeno-Cerdas et al. (2018) tested the hypothesis that seeding of absorbable sutures with genetically modified $C$. reinhardtii would promote wound healing immediately after surgical closure. Here, the authors demonstrated that the photosynthetic sutures were indeed capable of secreting significant amounts of bio-functional recombinant hVEGF, platelet-derived growth factor B (hPDGF-B) and stromal cell-derived factor-1 (hSDF-1), as well as releasing substantial levels of oxygen upon exposure to light (Centeno-Cerdas et al., 2018). Finally, Jarquín-Cordero et al. (2020) recently established an optimized platform for the secretion of alga-derived human growth factors and described the potentiating angiogenic effect of the combinatorial application of $C$. reinhardtii transgenic strains. All these results demonstrate the significant potential of transgenic photosynthetic organisms for the production of defined therapeutics for biomedical applications in the future.

\section{OUTLOOK}

Oxygen is not only vital for cellular respiration in untold numbers of living organisms including ourselves, it also plays a key role in the healing and regeneration of their tissues. Conversely, effective and safe oxygen perfusion represents one of the greatest challenges in the fields of organ transplantation, tissue engineering and chronic wound management. The many examples of photosymbiosis found in nature are the most compelling argument for the notion that the induction of photosynthesis in human tissues offers a feasible approach to the avoidance of tissue hypoxia in clinical settings. This has led to the exploration of photosynthesis as an alternative means of meeting the metabolic requirements of cells and tissues in the context of a variety of medical conditions, including respiratory failure, restoration of pancreatic function, cardiac ischemia and tissue regeneration.

Moreover, the potential of photosynthetic biomaterials for tissue engineering has just begun to be revealed. While all the examples mentioned in this review demonstrate that bioactivation of scaffolds with photosynthetic microorganisms can in principle provide a constant source of oxygen supply, some interesting findings suggest that they could further improve other parameters within established cell-culture systems, such as the removal of toxic metabolites or the secretion of beneficial secondary metabolites. Also, the parallel development of novel photosynthetic-cell encapsulation and immobilization technologies could further enhance photosynthetic cell therapy, as it should lead to general improvements in cultivation methods. Novel methods to combat tissue hypoxia in the field of tissue engineering are desperately needed, and if oxygenproducing photosynthetic biomaterials were able to fulfill this task, they might provide a means of accelerating the clinical application of bioartificial tissues. Besides, as already mentioned, the possibility of combining photosynthetic approaches with 
genetic engineering tools for transgene expression could enhance their clinical impact by providing for the local release of other therapeutic molecules, in addition to oxygen. Although proof-of-concept protocols have been described, well-established, standardized and efficient molecular tools that support a constructive biotechnological platform still have to be developed. Detailed characterization and a deeper understanding of specific promoters will be required to ensure that foreign gene expression can be precisely modulated in response to clinical needs.

Although the translation of these photosynthetic biomedical concepts to the clinic remains to be achieved, ongoing research shows how photosynthetic approaches may diversify and rapidly progress to breakthroughs in their clinical use in several fields of medicine. For instance, the induction of local photosynthesis could have a great impact on the economics of healthcare and supply currently unmet clinical needs for the stable oxygenation of partially or non-perfused organs. Indeed, some of the results discussed above suggest that photosynthetic oxygen supply could, in fact, enhance organ performance to levels above physiological normoxia, hereby opening possible medical applications for photosynthetic biotechnologies beyond the mitigation/rescue of ischemic conditions. However, to mimic photosymbiotic relationships for medical purposes, a better understanding of the cellular and molecular mechanisms that govern this process is urgently required. In this respect, one promising route to the successful implementation of this concept would be to capitalize on the broad biodiversity observed among photosynthetic organisms and carry out a massive screen for candidates that display the combinations of traits demanded by each different clinical application. Among the key parameters to be considered are features such as the appropriate shape, size and life cycle, as well as the light spectrum/intensity requirements for photosynthesis, and optimal growth temperature. Then, by providing a repertoire of safety-tested photosynthetic organisms with diverse optimal growth requirements and attributes, a better match could be found for every ischemic pathology, given thatbesides the lack of oxygen-issues such as excess of carbon dioxide, nutrient deprivation and accumulation of cellular waste may be relevant. For instance, exploring the applicability of other autotrophic organisms that have already evolved to maintain a photosymbiotic relationship with an animal host, such as dinoflagellates, could be a smart strategy in the search for valuable candidates for biomedical approaches. It is important to point out that, because oxygen production in photosymbiotic approaches relies on constant illumination, the development of novel illumination technologies to address issues such as heat relief and light penetration into different tissues presents a further set of challenges. Also, because most human tissues are not adapted to cope with light radiation, the possible role of phototoxicity in this context remains to be clarified. Nevertheless, the examples listed in Table 1 demonstrate that a customized illumination strategy for induced photosynthetic oxygen production may be developed for both internal and external human organs.

Whether one considers cell or tissue-level therapies, or applications to organ transplantation, the clinical success of photosymbiosis will strongly depend on the ability of the host immune system to handle the foreign photosynthetic symbionts.
Along with the systemic use of immunomodulatory drugs to induce tolerance, other standard technologies could be explored in more detail and adapted appropriately, including the use of inert biomaterials to encapsulate implanted heterologous cells and circumvent the host's immune response (Ashimova et al., 2019). In this context, alginate has demonstrated to be effective in protecting different cell types (Carroll et al., 2019; Ghanta et al., 2020) upon implantation, as well as more complex structures like pancreatic islets (Barkai et al., 2016). Besides, both microalgae and cyanobacteria could be genetically modified to locally release immunomodulatory factors, in addition to the compounds many of them already produce (Riccio and Lauritano, 2020), or as recently described, engineered to be coated with immunocompatible envelopes (Qiao et al., 2020). However, it would be far more interesting to search for immunotolerant photosynthetic microorganisms capable of establishing long-term relationships with humans. As discussed previously in this work, this idea is supported by evidence which indicates that vertebrate immune responses to photosynthetic organisms, even after systemic injection (Williams et al., 2020), are mild or non-existent. It is conceivable that the mammalian immune response might have evolved in the absence of the need to recognize photosynthetic cells as foreign entities (Wheeler et al., 2008). In addition, neither critical pathogen-associated molecular patterns compounds that are recognized by the native immune system (e.g., endotoxic LPS) nor toxic compounds are present in most of the photosynthetic microorganisms (Durai et al., 2015; Rosales-Mendoza et al., 2020). This raises hopes for the feasibility of establishing a photosymbiotic relationship resembling those utilized by reef-building corals, flatworms and adult salamanders. Even so, further in vitro and in vivo studies should address the detailed molecular mechanisms that govern this propitious immunotolerance between animals and photosynthetic cells. Other key questions that still need to be addressed concern the ability of photosynthetic biomaterials to fulfill all the local metabolic oxygen requirements, and the basic issue of the safety of this approach in human patients. In order to answer this last question, the first clinical trial (NCT03960164) has recently begun. However, no data have yet been released. Finally, a multidisciplinary approach based on close collaboration between basic scientists, clinicians and engineers will be required for the success of this approach; furthermore, owing to the possible implications of human photosynthesis beyond medicine, the transition from basic scientific research into clinical practice will require input from experts in public policy, ethics and economics.

\section{AUTHOR CONTRIBUTIONS}

MC: conceptualization, investigation, project administration, and writing-original draft. NM: investigation and writingoriginal draft. TS: resources and funding acquisition. JE: conceptualization, visualization, writing-review, and editing. JN: conceptualization, writing-original draft, resources, and funding acquisition. All authors contributed to the article and approved the submitted version. 


\section{FUNDING}

This work was funded by the Deutsche Forschungsgemeinschaft (FOR2092 Ni390/9-2; SFB TRR175-A06).

\section{REFERENCES}

Agapakis, C. M., Niederholtmeyer, H., Noche, R. R., Lieberman, T. D., Megason, S. G., Way, J. C., et al. (2011). Towards a synthetic chloroplast. PLoS One 6:e18877. doi: 10.1371/journal.pone.0018877

Alvarez, M., Reynaert, N., Chávez, M. N., Aedo, G., Araya, F., Hopfner, U., et al. (2015). Generation of Viable Plant-Vertebrate Chimeras. PLoS One 10:e0130295. doi: 10.1371/journal.pone.0130295

Ashimova, A., Yegorov, S., Negmetzhanov, B., and Hortelano, G. (2019). Cell Encapsulation Within Alginate Microcapsules: Immunological Challenges and Outlook. Front. Bioengin. Biotechnol. 7:380. doi: 10.3389/fbioe.2019.00380

Atkinson, M., Eisenbarth, G., and Michels, A. (2014). Type 1 diabetes. Lancet 383, 69-82. doi: 10.1016/S0140-6736(13)60591-7

Baek, K., Lee, Y., Nam, O., Park, S., Sim, S., and Jin, E. (2016). Introducing Dunaliella LIP promoter containing light-inducible motifs improves transgenic expression in Chlamydomonas reinhardtii. Biotechnol. J. 11, 384-392. doi: 10.1002/biot.201500269

Baier, T., Kros, D., Feiner, R. C., Lauersen, K. J., Müller, K. M., and Kruse, O. (2018). Engineered Fusion Proteins for Efficient Protein Secretion and Purification of a Human Growth Factor from the Green Microalga Chlamydomonas reinhardtii. ACS Synth Biol. 7, 2547-2557. doi: 10.1021/acssynbio.8b00226

Bailly, X., Laguerre, L., Correc, G., Dupont, S., Kurth, T., Pfannkuchen, A., et al. (2014). The chimerical and multifaceted marine acoel Symsagittifera roscoffensis: from photosymbiosis to brain regeneration. Front. Microbiol. 5:498. doi: $10.3389 /$ fmicb. 2014.00498

Barkai, U., Rotem, A., and de Vos, P. (2016). Survival of encapsulated islets: More than a membrane story. World J. Transpl. 6, 69-90. doi: 10.5500/wjt.v6.i1.69

Basu, S., Salley, S. O., Whittlesey, G. C., and Klein, M. D. (1994). Feasibility studies for a photosynthetic artificial lung. Optim. Paramet. Affect. Photosynth. ASAIO J. 40, M743-M746. doi: 10.1097/00002480-199407000-00098

Basu-Dutt, S., Fandino, M. R., Salley, S. O., Thompson, I. M., Whittlesey, G. C., and Klein, M. D. (1997). Feasibility of a photosynthetic artificial lung. ASAIO J. 43, 279-283. doi: 10.1097/00002480-199743040-00004

Bloch, K., Papismedov, E., Yavriyants, K., Vorobeychik, M., Beer, S., and Vardi, P. (2006). Photosynthetic oxygen generator for bioartificial pancreas. Tissue Eng 12, 337-344. doi: 10.1089/ten.2006.12.337

Boerema, I., Meyne, N. G., Brummelkamp, W. K., Bouma, S., Mensch, M. H., Kamermans, F., et al. (1960). Life without blood]. Nederl. Tijdschr. Voor Geneeskd. 104, 949-954.

Burns, J., Zhang, H., Hill, E., Kim, E., and Kerney, R. (2017). Transcriptome analysis illuminates the nature of the intracellular interaction in a vertebratealgal symbiosis. eLife 6:e22054. doi: 10.7554/eLife.22054.049

Carroll, L., Mridha, A. R., and Tuch, B. E. (2019). Encapsulation and Transplantation of Pancreatic Progenitor Cells. Methods Mol. Biol. 2029, 93102. doi: 10.1007/978-1-4939-9631-5_8

Centeno-Cerdas, C., Jarquín-Cordero, M., Chávez, M. N., Hopfner, U., Holmes, C., Schmauss, D., et al. (2018). Development of photosynthetic sutures for the local delivery of oxygen and recombinant growth factors in wounds. Acta Biomater. 81, 184-194. doi: 10.1016/j.actbio.2018.09.060

Chávez, M. N., Schenck, T. L., Hopfner, U., Centeno-Cerdas, C., SomlaiSchweiger, I., Schwarz, C., et al. (2016). Towards autotrophic tissue engineering: Photosynthetic gene therapy for regeneration. Biomaterials 75, 25-36. doi: 10.1016/j.biomaterials.2015.10.014

Chen, H., Cheng, Y., Tian, J., Yang, P., Zhang, X., Chen, Y., et al. (2020). Dissolved oxygen from microalgae-gel patch promotes chronic wound healing in diabetes. Sci. Adv. 6:eaba4311. doi: 10.1126/sciadv.aba4311

Cohen, J. E., Goldstone, A. B., Paulsen, M. J., Shudo, Y., Steele, A. N., Edwards, B. B., et al. (2017). An innovative biologic system for photon-powered myocardium in the ischemic heart. Sci. Adv. 3:e1603078. doi: 10.1126/sciadv. 1603078

\section{ACKNOWLEDGMENTS}

We would like to thank David Necuñir (PUC, Chile) for his technical assistance in the preparation of the figures.

Colom, A., Galgoczy, R., Almendros, I., Xaubet, A., Farré, R., and Alcaraz, J. (2014). Oxygen diffusion and consumption in extracellular matrix gels: implications for designing three-dimensional cultures. J. Biomed. Mater Res. A 102, 2776-2784. doi: 10.1002/jbm.a.34946

De Smet, G. H. J. H., Kroese, L. F., Menon, A. G., Jeekel, J., van Pelt, A. W. J. W., Kleinrensink, G.-J. J., et al. (2017). Oxygen therapies and their effects on wound healing. Wound Rep. Reg. 25, 591-608. doi: 10.1111/wrr.12561

Dehghani, J., Adibkia, K., Movafeghi, A., Maleki-Kakelar, H., Saeedi, N., and Omidi, Y. (2019). Towards a new avenue for producing therapeutic proteins: Microalgae as a tempting green biofactory. Biotechnol. Adv. 40:107499. doi: 10.1016/j.biotechadv.2019.107499

Doonan, S. A., and Gooday, G. W. (1982). Ecological Studies of Symbiosis in Convoluta roscoffensis. Mar. Ecol. Progr. Ser. 8, 69-73. doi: 10.3354/ meps008069

Durai, P., Batool, M., and Choi, S. (2015). Structure and Effects of Cyanobacterial Lipopolysaccharides. Mar. Drug. 13, 4217-4230. doi: 10.3390/md13074217

Eisenbud, D. E. (2012). Oxygen in wound healing: nutrient, antibiotic, signaling molecule, and therapeutic agent. Clin. Plast. Surg. 39, 293-310. doi: 10.1016/j. cps.2012.05.001

Eladel, H., Abomohra, A. E., Battah, M., Mohmmed, S., Radwan, A., and Abdelrahim, H. (2019). Evaluation of Chlorella sorokiniana isolated from local municipal wastewater for dual application in nutrient removal and biodiesel production. Bioproc. Biosyst Eng. 42, 425-433. doi: 10.1007/s00449-018-2046-5

Feng, G., Dong, S., Huang, M., Zeng, M., Liu, Z., Zhao, Y., et al. (2018a). Biogenic Polyphosphate Nanoparticles from a Marine Cyanobacterium Synechococcus sp. PCC 7002: Production, Characterization, and Anti-Inflammatory Properties In Vitro. Mar. Drugs 16:322. doi: 10.3390/md16090322

Feng, G., Feng, Y., Guo, T., Yang, Y., Guo, W., Huang, M., et al. (2018b) Biogenic Polyphosphate Nanoparticles from Synechococcus sp. PCC 7002 Exhibit Intestinal Protective Potential in Human Intestinal Epithelial Cells In Vitro and Murine Small Intestine Ex Vivo. J. Agric. Food Chem. 66, 8026-8035. doi: 10.1021/acs.jafc.8b03381

Feng, G., Zeng, M., Huang, M., Zhu, S., Guo, W., and Wu, H. (2019). Protective effect of biogenic polyphosphate nanoparticles from Synechococcus sp. PCC 7002 on dextran sodium sulphate-induced colitis in mice. Food Funct. 10, 1007-1016. doi: 10.1039/c8fo01861h

Fields, F., Lejzerowicz, F., Schroeder, D., Ngoi, S., Tran, M., McDonald, D., et al. (2020). Effects of the microalgae Chlamydomonas on gastrointestinal health J. Func. Foods 65:103738. doi: 10.1016/j.jff.2019.103738

Gateau, H., Solymosi, K., Marchand, J., and Schoefs, B. (2017). Carotenoids of Microalgae Used in Food Industry and Medicine. Mini Rev. Med. Chem. 17, 1140-1172. doi: 10.2174/1389557516666160808123841

Ghanta, R. K., Aghlara-Fotovat, S., Pugazenthi, A., Ryan, C. T., Singh, V. P., Mathison, M., et al. (2020). Immune-modulatory alginate protects mesenchymal stem cells for sustained delivery of reparative factors to ischemic myocardium. Biomater. Sci. 2020:32797143. doi: 10.1039/D0BM00855A

Gibly, R. F., Graham, J. G., Luo, X., Lowe, W. L. Jr., Hering, B. J., and Shea, L. D. (2011). Advancing islet transplantation: from engraftment to the immune response. Diabetologia 54, 2494-2505. doi: 10.1007/s00125-011-2243-0

Gilbert, P. (1942). Observations on the Eggs of Ambystoma Maculatum with Especial Reference to the Green Algae Found Within the Egg Envelopes. Ecology 23, 215-227. doi: $10.2307 / 1931088$

Gilbert, P. (1944). The Alga-Egg Relationship in Ambystoma Maculatum, A Case of Symbiosis. Ecology 25, 366-369. doi: 10.2307/1931284

Giorgakis, E., Mathur, A., Chakkera, H., Reddy, K., Moss, A., and Singer, A. (2018). Solid pancreas transplant: Pushing forward. World J. Transpl. 8, 237-251. doi: 10.5500/wjt.v8.i7.237

Gordillo, G. M., Hunt, T. K., and Sen, C. K. (2003). Significance of oxygen therapeutics. Wound Rep. Regen. 11:393. ; author reply 393. doi: 10.1046/j.1524475X.2003.11513.x 
Graham, E. R., Fay, S. A., Davey, A., and Sanders, R. W. (2013). Intracapsular algae provide fixed carbon to developing embryos of the salamander Ambystoma maculatum. J. Exp. Biol. 216, 452-459. doi: 10.1242/jeb.076711

Gregory, J., and Mayfield, S. (2014). Developing inexpensive malaria vaccines from plants and algae. Appl. Microbiol. Biotechnol. 98, 1983-1990. doi: 10.1007/ s00253-013-5477-6

Habetha, M., Anton-Erxleben, F., Neumann, K., and Bosch, T. C. (2003). The Hydra viridis/Chlorella symbiosis. Grow. sex. Differ. Poly. without Symb. Zool. 106, 101-108. doi: 10.1078/0944-2006-00104

Haiden, S. A., Hoffmann, J. H., and Cramer, M. D. (2012). Benefits of photosynthesis for insects in galls. Oecologia 170, 987-997. doi: 10.1007/ s00442-012-2365-1

Haraguchi, Y., Kagawa, Y., Sakaguchi, K., Matsuura, K., Shimizu, T., and Okano, T. (2017). Thicker three-dimensional tissue from a "symbiotic recycling system" combining mammalian cells and algae. Sci. Rep. 7:41594. doi: 10.1038/ srep41594

Hempel, F., Lau, J., Klingl, A., and Maier, U. G. (2011). Algae as protein factories: expression of a human antibody and the respective antigen in the diatom Phaeodactylum tricornutum. PLoS One 6:e28424. doi: 10.1371/journal.pone. 0028424

Hempel, F., and Maier, U. (2012). An engineered diatom acting like a plasma cell secreting human IgG antibodies with high efficiency. Microbial. Cell Fact. 11:126. doi: 10.1186/1475-2859-11-126

Hempel, F., Maurer, M., Brockmann, B., Mayer, C., Biedenkopf, N., Kelterbaum, A., et al. (2017). From hybridomas to a robust microalgal-based production platform: molecular design of a diatom secreting monoclonal antibodies directed against the Marburg virus nucleoprotein. Microbial. Cell Fact. 16:131 doi: 10.1186/s12934-017-0745-2

Hill, R., Szabó, M., ur Rehman, A., Vass, I., Ralph, P. J., and Larkum, A. W. (2014). Inhibition of photosynthetic CO2 fixation in the coral Pocillopora damicornis and its relationship to thermal bleaching. J. Exp. Biol. 217, 2150-2162. doi: 10.1242/jeb.100578

Hohmann-Marriott, M. F., and Blankenship, R. E. (2011). Evolution of photosynthesis. Annu. Rev. Plant Biol. 62, 515-548. doi: 10.1146/annurevarplant-042110-103811

Hopfner, U., Schenck, T.-L. L., Chávez, M.-N. N., Machens, H.-G. G., Bohne, A.V. V., Nickelsen, J., et al. (2014). Development of photosynthetic biomaterials for in vitro tissue engineering. Acta Biomater 10, 2712-2717. doi: 10.1016/j. actbio.2013.12.055

Iacopino, S., Jurinovich, S., Cupellini, L., Piccinini, L., Cardarelli, F., Perata, P., et al. (2019). A Synthetic Oxygen Sensor for Plants Based on Animal Hypoxia Signaling. Plant Physiol. 179, 986-1000. doi: 10.1104/pp.18.01003

Ishikawa, M., Yuyama, I., Shimizu, H., Nozawa, M., Ikeo, K., and Gojobori, T. (2016). Different Endosymbiotic Interactions in Two Hydra Species Reflect the Evolutionary History of Endosymbiosis. Genom. Biol. Evol. 8, 2155-2163. doi: 10.1093/gbe/evw142

Iyer, R. K., Radisic, M., Cannizzaro, C., and Vunjak-Novakovic, G. (2007). Synthetic oxygen carriers in cardiac tissue engineering. Artif Cells Blood Sub. Immob. Biotechnol. 35, 135-148. doi: 10.1080/10731190600974988

Jarquín-Cordero, M., Chávez, M. N., Centeno-Cerdas, C., Bohne, A.-V. V., Hopfner, U., Machens, H.-G. G., et al. (2020). Towards a biotechnological platform for the production of human pro-angiogenic growth factors in the green alga Chlamydomonas reinhardtii. Appl. Microbiol. Biotechnol. 104, 725739. doi: 10.1007/s00253-019-10267-6

Jones, C. W., Mastrangelo, I. A., Smith, H. H., Liu, H. Z., and Meck, R. A. (1976). Interkingdom fusion between human (HeLa) cells and tobacco hybrid (GGLL) protoplasts. Science 193, 401-403. doi: 10.1126/science.935875

Kerney, R. (2011). Symbioses between salamander embryos and green algae. Symbiosis 54, 107-117. doi: 10.1007/s13199-011-0134-2

Kerney, R., Kim, E., Hangarter, R., Heiss, A., Bishop, C., and Hall, B. (2011). Intracellular invasion of green algae in a salamander host. Proc. National. Acad. Sci. 108, 6497-6502. doi: 10.1073/pnas.1018259108

Kim, P. J., Heilala, M., Steinberg, J. S., and Weinraub, G. M. (2007). Bioengineered alternative tissues and hyperbaric oxygen in lower extremity wound healing. Clin. Podiatr. Med. Surg. 24, 529-546. doi: 10.1016/j.cpm.2007. 03.011

Kimmel, H. M., Grant, A., and Ditata, J. (2016). The Presence of Oxygen in Wound Healing. Wounds 28, 264-270.
Klein, S. G., Pitt, K. A., Nitschke, M. R., Goyen, S., Welsh, D. T., Suggett, D. J., et al. (2017). Symbiodinium mitigate the combined effects of hypoxia and acidification on a noncalcifying cnidarian. Glob. Chang. Biol. 23, 3690-3703. doi: $10.1111 /$ gcb.13718

Krujatz, F., Lode, A., Brüggemeier, S., Schütz, K., Kramer, J., Bley, T., et al. (2015). Green bioprinting: Viability and growth analysis of microalgae immobilized in 3D-plotted hydrogels versus suspension cultures. Engin. Life Sci. 15, 678-688. doi: 10.1002/elsc.201400131

Kühlmann (1993). Coral Reefs. Ed. Z. Dubinsky. Ecosystems of the World 25. 550 pp., 100 Figs., 61 tabs., hard cover. - Amsterdam Oxford New York Tokyo: Elsevier 1990. ISBN 0-444-87392-9 (Vol. 25). USS 220. Dfl 385.-. Internat. Rev. Der Gesam. Hydrobiol. Hydrogr. 78, 160-160 . doi: 10.1002/iroh.19930780117

Kumar, J., Singh, D., Tyagi, M., and Kumar, A. (2019). Cyanobacteria: Applications in Biotechnology. Amsterdam: Elsevier Inc. doi: 10.1016/B978-0-12-814667-5. 00016-7

Lee, S., Lee, Y., Choi, S., Park, S.-B., Tran, Q.-G., Heo, J., et al. (2018). Development of an alcohol-inducible gene expression system for recombinant protein expression in Chlamydomonas reinhardtii. J. Appl. Phycol. 30, 2297-2304. doi: 10.1007/s10811-018-1480-8

Lode, A., Krujatz, F., Brüggemeier, S., Quade, M., Schütz, K., Knaack, S., et al. (2015). Green bioprinting: Fabrication of photosynthetic algae-laden hydrogel scaffolds for biotechnological and medical applications. Engin. Life Sci. 15, 177-183. doi: 10.1002/elsc.201400205

Ludwig, M., and Bryant, D. (2012). Synechococcus sp. Strain PCC 7002 Transcriptome: Acclimation to Temperature, Salinity, Oxidative Stress, and Mixotrophic Growth Conditions. Front. Microbiol. 3:354. doi: 10.3389/fmicb. 2012.00354

Makdisi, G., and Wang, I.-W. W. (2015). Extra Corporeal Membrane Oxygenation (ECMO) review of a lifesaving technology. J. Thorac. Dis. 7, E166-E176.

Malda, J., Klein, T. J., and Upton, Z. (2007). The roles of hypoxia in the in vitro engineering of tissues. Tissue Eng. 13, 2153-2162. doi: 10.1089/ten.2006.0417

Mayfield, S., and Golden, S. S. (2015). Photosynthetic bio-manufacturing: food, fuel, and medicine for the 21st century. Photosyn. Res. 123, 225-226. doi: 10.1007/s11120-014-0063-z

Melo Clavijo, J., Donath, A., Serôdio, J., and Christa, G. (2018). Polymorphic adaptations in metazoans to establish and maintain photosymbioses. Biol. Rev. Camb. Philos. Soc. 93, 2006-2020. doi: 10.1111/brv.12430

Melrose, J. (2016). Glycosaminoglycans in Wound Healing. Bone Tissue Regen. Insights 7, 29-50. doi: 10.4137/BTRI.S38670

Molino, J., Alves, T., Ferreira-Camargo, L., Croce, M., Tanaka, A., Buson, F., et al. (2016). Chimeric spider silk production in microalgae: a modular bionanomaterial. Res. Ideas Outc. 2:e9342. doi: 10.3897/rio.2.e9342

Morimoto, T., Nagatsu, A., Murakami, N., Sakakibara, J., Tokuda, H., Nishino, H., et al. (1995). Anti-tumour-promoting glyceroglycolipids from the green alga. Chlor. Vulgar. Phytochem. 40, 1433-1437. doi: 10.1016/0031-9422(95)00458-j

Mourelle, M. L., Gómez, C., and Legido, J. (2017). The Potential Use of Marine Microalgae and Cyanobacteria in Cosmetics and Thalassotherapy. Cosmetics 4:46. doi: 10.3390/cosmetics4040046

Mysliwa-Kurdziel, B., and Solymosi, K. (2017). Phycobilins and Phycobiliproteins Used in Food Industry and Medicine. Mini Rev. Med. Chem. 17, 1173-1193. doi: 10.2174/1389557516666160912180155

Nickelsen, J., and Rengstl, B. (2013). Photosystem II assembly: from cyanobacteria to plants. Annu. Rev. Plant Biol. 64, 609-635. doi: 10.1146/annurev-arplant050312-120124

Ota, M., Takenaka, M., Sato, Y., Smith, R. L., and Inomata, H. (2015a). Effects of light intensity and temperature on photoautotrophic growth of a green microalga. Chlor. Littor. Biotechnol. Rep. 7, 24-29. doi: 10.1016/j.btre.2015. 05.001

Ota, M., Takenaka, M., Sato, Y., Smith, R. L., and Inomata, H. (2015b). Variation of photoautotrophic fatty acid production from a highly $\mathrm{CO} 2$ tolerant alga, Chlorococcum littorale, with inorganic carbon over narrow ranges of $\mathrm{pH}$. Biotechnol. Prog. 31, 1053-1057. doi: 10.1002/btpr.2099

Priestley, J. (1772). XIX. Observations on different kinds of air. London: Philosophical Transactions of the Royal Society of London, 147-264. doi: 10. 1098/rstl.1772.0021

Qiao, Y., Yang, F., Xie, T., Du, Z., Zhong, D., Qi, Y., et al. (2020). Engineered algae: A novel oxygen-generating system for effective treatment of hypoxic cancer. Sci. Adv. 6:eaba5996. doi: 10.1126/sciadv.aba5996 
Ramos-Martinez, E. M., Fimognari, L., and Sakuragi, Y. (2017). High-yield secretion of recombinant proteins from the microalga Chlamydomonas reinhardtii. Plant Biotechnol. J. 15, 1214-1224. doi: 10.1111/pbi.12710

Rasala, B. A., and Mayfield, S. P. (2015). Photosynthetic biomanufacturing in green algae; production of recombinant proteins for industrial, nutritional, and medical uses. Photosyn. Res. 123, 227-239. doi: 10.1007/s11120-014-9994-7

Riccio, G., and Lauritano, C. (2020). Microalgae with Immunomodulatory Activities. Mar. Drug 18:2. doi: 10.3390/md18010002

Rodriguez, P. G., Felix, F. N., Woodley, D. T., and Shim, E. K. (2008). The role of oxygen in wound healing: a review of the literature. Dermatol. Surg. 34, 1159-1169. doi: 10.1111/j.1524-4725.2008.34254.x

Rosales-Mendoza, S. (2016). Algae-Based Biopharmaceuticals. Berlin: Springer. doi: 10.1007/978-3-319-32232-2

Rosales-Mendoza, S., Solís-Andrade, K., Márquez-Escobar, V., González-Ortega, O., and Bañuelos-Hernandez, B. (2020). Current advances in the algae-made biopharmaceuticals field. Exp. Opin. Biol. Ther. 20, 751-766. doi: 10.1080/ 14712598.2020.1739643

Ruffing, A., Jensen, T., and Strickland, L. (2016). Genetic tools for advancement of Synechococcus sp. PCC 7002 as a cyanobacterial chassis. Microb. Cell Fact. 15:190. doi: 10.1186/s12934-016-0584-6

Sanford, N. E., Wilkinson, J. E., Nguyen, H., Diaz, G., and Wolcott, R. (2018). Efficacy of hyperbaric oxygen therapy in bacterial biofilm eradication. J. Wound Care 27, S20-S28. doi: 10.12968/jowc.2018.27.Sup1.S20

Sarnaik, A., Abernathy, M., Han, X., Ouyang, Y., Xia, K., Chen, Y., et al. (2019). Metabolic engineering of cyanobacteria for photoautotrophic production of heparosan, a pharmaceutical precursor of heparin. Algal Res. 37, 57-63. doi: 10.1016/j.algal.2018.11.010

Sarnaik, A., Pandit, R., and Lali, A. (2017). Growth engineering of Synechococcus elongatus PCC 7942 for mixotrophy under natural light conditions for improved feedstock production. Biotechnol. Prog. 33, 1182-1192. doi: 10.1002/ btpr. 2490

Satoh, A., Kurano, N., Senger, H., and Miyachi, S. (2002). Regulation of energy balance in photosystems in response to changes in $\mathrm{CO} 2$ concentrations and light intensities during growth in extremely-high-CO2-tolerant green microalgae. Plant Cell Physiol. 43, 440-451. doi: 10.1093/pcp/pcf054

Scaife, M. A., Nguyen, G. T. D. T., Rico, J., Lambert, D., Helliwell, K. E., and Smith, A. G. (2015). Establishing Chlamydomonas reinhardtii as an industrial biotechnology host. Plant J. 82, 532-546. doi: 10.1111/tpj.12781

Schenck, T. L., Hopfner, U., Chávez, M. N., Machens, H.-G. G., Somlai-Schweiger, I., Giunta, R. E., et al. (2015). Photosynthetic biomaterials: a pathway towards autotrophic tissue engineering. Acta Biomater 15, 39-47. doi: 10.1016/j.actbio. 2014.12.012

Schroda, M., Beck, C., and Vallon, O. (2002). Sequence elements within an HSP70 promoter counteract transcriptional transgene silencing in Chlamydomonas. Plant J. 31, 445-455. doi: 10.1046/j.1365-313x.2002.01371.x

Seidel, J., Ahlfeld, T., Adolph, M., Kümmritz, S., Steingroewer, J., Krujatz, F., et al. (2017). Green bioprinting: extrusion-based fabrication of plant cell-laden biopolymer hydrogel scaffolds. Biofabrication 9:045011. doi: 10.1088/1758$5090 /$ aa8854

Sen, C. K. (2009). Wound healing essentials: let there be oxygen. Wound Rep. Reg. 17, 1-18. doi: 10.1111/j.1524-475x.2008.00436.x

Shen, J.-R. R. (2015). The Structure of Photosystem II and the Mechanism of Water Oxidation in Photosynthesis. Annu. Rev. Plant Biol. 66, 23-48. doi: 10.1146/annurev-arplant-050312-120129

Shimizu, T., Sekine, H., Yang, J., Isoi, Y., Yamato, M., Kikuchi, A., et al. (2006). Polysurgery of cell sheet grafts overcomes diffusion limits to produce thick, vascularized myocardial tissues. FASEB J. 20, 708-710. doi: 10.1096/fj.054715fje

Singh, R., Parihar, P., Singh, M., Bajguz, A., Kumar, J., Singh, S., et al. (2017). Uncovering Potential Applications of Cyanobacteria and Algal Metabolites in Biology, Agriculture and Medicine: Current Status and Future Prospects. Front. Microbiol. 8:515. doi: 10.3389/fmicb.2017.00515
Small, D., Bennett, S., and Bishop, C. (2014). The roles of oxygen and ammonia in the symbiotic relationship between the spotted salamander Ambystoma maculatum and the green alga Oophila amblystomatis during embryonic development. Symbiosis 64, 1-10. doi: 10.1007/s13199-014-0297-8

Stoffels, L., Taunt, H. N., Charalambous, B., and Purton, S. (2017). Synthesis of bacteriophage lytic proteins against Streptococcus pneumoniae in the chloroplast of Chlamydomonas reinhardtii. Plant Biotechnol. J. 15, 1130-1140. doi: $10.1111 /$ pbi. 12703

Tattersall, G., and Spiegelaar, N. (2008). Embryonic motility and hatching success of Ambystoma maculatum are influenced by a symbiotic alga. Canad. J. Zool. 86, 1289-1298. doi: 10.1139/z08-115

Thom, S. R. (2011). Hyperbaric oxygen: its mechanisms and efficacy. Plast. Reconstr. Surg. 127(Suppl. 1), 131S-141S. doi: 10.1097/PRS.0b013e3181fbe2bf

Vijayakumar, S., and Menakha, M. (2015). Pharmaceutical applications of cyanobacteria-A review. J. Acute Med. 5, 15-23. doi: 10.1016/j.jacme.2015. 02.004

Wada, N., Kazuki, Y., Kazuki, K., Inoue, T., Fukui, K., and Oshimura, M. (2016). Maintenance and Function of a Plant Chromosome in Human Cells. ACS Synth. Biol. 6, 301-310. doi: 10.1021/acssynbio.6b00180

Wheeler, G., Miranda-Saavedra, D., and Barton, G. (2008). Genome Analysis of the Unicellular Green Alga Chlamydomonas reinhardtii Indicates an Ancient Evolutionary Origin for Key Pattern Recognition and Cell-Signaling Protein Families. Genetics 179, 193-197. doi: 10.1534/genetics.107.08 5936

Wijffels, R. H. H., Kruse, O., and Hellingwerf, K. J. (2013). Potential of industrial biotechnology with cyanobacteria and eukaryotic microalgae. Curr. Opin. Biotechnol. 24, 405-413. doi: 10.1016/i.copbio.2013.04.004

Williams, K. M., Wang, H., Paulsen, M. J., Thakore, A. D., Rieck, M., Lucian, H. J., et al. (2020). Safety of photosynthetic Synechococcus elongatus for in vivo cyanobacteria-mammalian symbiotic therapeutics. Microb. Biotechnol. 2020:32476224. doi: 10.1111/1751-7915.13596

Yamaoka, I., Kikuchi, T., Arata, T., and Kobayashi, E. (2012). Organ preservation using a photosynthetic solution. Transpl. Res. 1:2. doi: 10.1186/2047-1440-1-2

Yu, J., Liberton, M., Cliften, P. F., Head, R. D., Jacobs, J. M., Smith, R. D., et al. (2015). Synechococcus elongatus UTEX 2973, a fast growing cyanobacterial chassis for biosynthesis using light and CO2. Sci. Rep. 5:8132. doi: 10.1038/ srep08132

Zhang, L., Selão, T., Nixon, P., and Norling, B. (2019). Photosynthetic conversion of $\mathrm{CO} 2$ to hyaluronic acid by engineered strains of the cyanobacterium Synechococcus sp. PCC 7002. Algal Res. 44:101702. doi: 10.1016/j.algal.2019. 101702

Zoccola, D., Morain, J., Pagès, G., Caminiti-Segonds, N., Giuliano, S., Tambutté, S., et al. (2017). Structural and functional analysis of coral Hypoxia Inducible Factor. PLoS One 12:e0186262. doi: 10.1371/journal.pone.0186262

Conflict of Interest: JE was the founder and VP of Technology at SymbiOx Inc. This startup did not provide any financial support to this work but is closely related to some topics of this manuscript. In addition, he was currently supervising an ongoing clinical trial (NCT03960164) to prove the safety of the implantation of photosynthetic scaffolds in wounds that result from trauma injuries.

The remaining authors declare that the research was conducted in the absence of any commercial or financial relationships that could be construed as a potential conflict of interest.

Copyright (c) 2020 Chávez, Moellhoff, Schenck, Egaña and Nickelsen. This is an open-access article distributed under the terms of the Creative Commons Attribution License (CC BY). The use, distribution or reproduction in other forums is permitted, provided the original author(s) and the copyright owner(s) are credited and that the original publication in this journal is cited, in accordance with accepted academic practice. No use, distribution or reproduction is permitted which does not comply with these terms. 